\title{
Small-scale spatio-temporal characteristics of accumulation rates in western Dronning Maud Land, Antarctica
}

\author{
Helgard ANSCHÜTZ, ${ }^{1 *}$ Daniel STEINHAGE, ${ }^{1}$ Olaf EISEN, ${ }^{1}$ Hans OERTER, ${ }^{1}$ \\ Martin HORWATH, ${ }^{2}$ Urs RUTH ${ }^{1}$ \\ ${ }^{1}$ Alfred-Wegener-Institut für Polar- und Meeresforschung, Postfach 120161, D-27515 Bremerhaven, Germany \\ E-mail: helgard.anschuetz@npolar.no \\ ${ }^{2}$ Institut für Planetare Geodäsie, Technische Universität Dresden, D-01062 Dresden, Germany
}

\begin{abstract}
Spatio-temporal variations of the recently determined accumulation rate are investigated using ground-penetrating radar (GPR) measurements and firn-core studies. The study area is located on Ritscherflya in western Dronning Maud Land, Antarctica, at an elevation range 1400-1560 m. Accumulation rates are derived from internal reflection horizons (IRHs), tracked with GPR, which are connected to a dated firn core. GPR-derived internal layer depths show small relief along a $22 \mathrm{~km}$ profile on an ice flowline. Average accumulation rates are about $190 \mathrm{~kg} \mathrm{~m}^{-2} \mathrm{a}^{-1}(1980-2005)$ with spatial variability $(1 \sigma)$ of $5 \%$ along the GPR profile. The interannual variability obtained from four dated firn cores is one order of magnitude higher, showing $1 \sigma$ standard deviations around $30 \%$. Mean temporal variations of GPRderived accumulation rates are of the same magnitude or even higher than spatial variations. Temporal differences between 1980-90 and 1990-2005, obtained from two dated IRHs along the GPR profile, indicate temporally non-stationary processes, linked to spatial variations. Comparison with similarly obtained accumulation data from another coastal area in central Dronning Maud Land confirms this observation. Our results contribute to understanding spatio-temporal variations of the accumulation processes, necessary for the validation of satellite data (e.g. altimetry studies and gravity missions such as Gravity Recovery and Climate Experiment (GRACE)).
\end{abstract}

\section{INTRODUCTION}

Recent years have seen increasing discussions of observations of sea-level change (e.g. Van der Veen, 2002; Thomas and others, 2004; Alley and others, 2005; Church and White, 2006) and analysis of future sea-level rise (Gregory and Huybrechts, 2006). Uncertainties are still high, with the largest introduced by the contribution of the Antarctic ice sheet (e.g. Rignot and Thomas, 2002; Vaughan, 2005). New satellite missions such as the Gravity Recovery and Climate Experiment (GRACE; Tapley and others, 2004), the Ice, Cloud, and Land Elevation Satellite (ICESat; Zwally and others, 2002) and the forthcoming CryoSat-2 are expected to provide new insights into Antarctica's mass balance, especially in coastal and mountainous areas where European Remote-sensing Satellite (ERS) data could not determine surface elevation changes due to the steep slopes (Vaughan, 2005). Several recent studies report mass change rates for the West Antarctic and East Antarctic ice sheets (WAIS and EAIS) from GRACE. Although these studies generally agree that the WAIS is losing mass while the EAIS is gaining mass or is at least close to balance, their individual estimates yield different results (Table 1).

In the data presented by Velicogna and Wahr (2006), a significant ice-mass trend is only apparent after the removal of postglacial rebound from the GRACE solutions. Such corrections depend largely upon the models adopted for postglacial rebound, and thus form the main uncertainty in the ice-mass changes obtained from GRACE (Chen and others, 2006). The uncertainties and the differences highlight the

*Present address: Norwegian Polar Institute, Polar Environmental Center, NO-9005 Tromsø, Norway. necessity of obtaining ground-truth data for the estimates of ice-mass changes based on satellite gravity and altimetry data. Furthermore, ice-mass changes derived from GRACE are averaged over several hundred kilometres; small-scale effects are therefore not resolvable. Small-scale variations in parameters affecting the mass balance of the ice sheet are of major importance in validating satellite data. Together with the effects of ice dynamics, spatial and temporal variations of accumulation rates and density influence changes in icesheet elevation. It is therefore crucial to investigate these parameters and their spatio-temporal changes on small scales by ground-based observations.

Accumulation data have often been derived from point measurements such as firn cores, snow pits or stake readings (e.g. Isaksson and Karlén, 1994; Melvold and others, 1998; Oerter and others, 1999; Kreutz and others, 2000). However, these only yield accumulation data at the probing location, leaving open the question of spatial representation as discussed by Richardson and Holmlund (1999). They recommend ground-penetrating radar (GPR) studies in order to investigate the spatial variability of accumulation rates around a drilling site. GPR has been widely applied in such a way in recent years (e.g. Richardson and others, 1997; Sinisalo and others, 2003; Rotschky and others, 2004; Spikes and others, 2004; Eisen and others, 2005).

The observed internal reflection horizons (IRHs) are due to contrasting values of dielectric permittivity in the subsurface. Ice density has the most significant influence in the upper hundreds of metres of the firn/ice column, affecting the real part of the dielectric permittivity (e.g. Fujita and others, 1999). IRHs were demonstrated to be isochronous (Eisen and others, 2004; Vaughan and others, 2004). From their estimated age and a density-depth distribution, the mean 

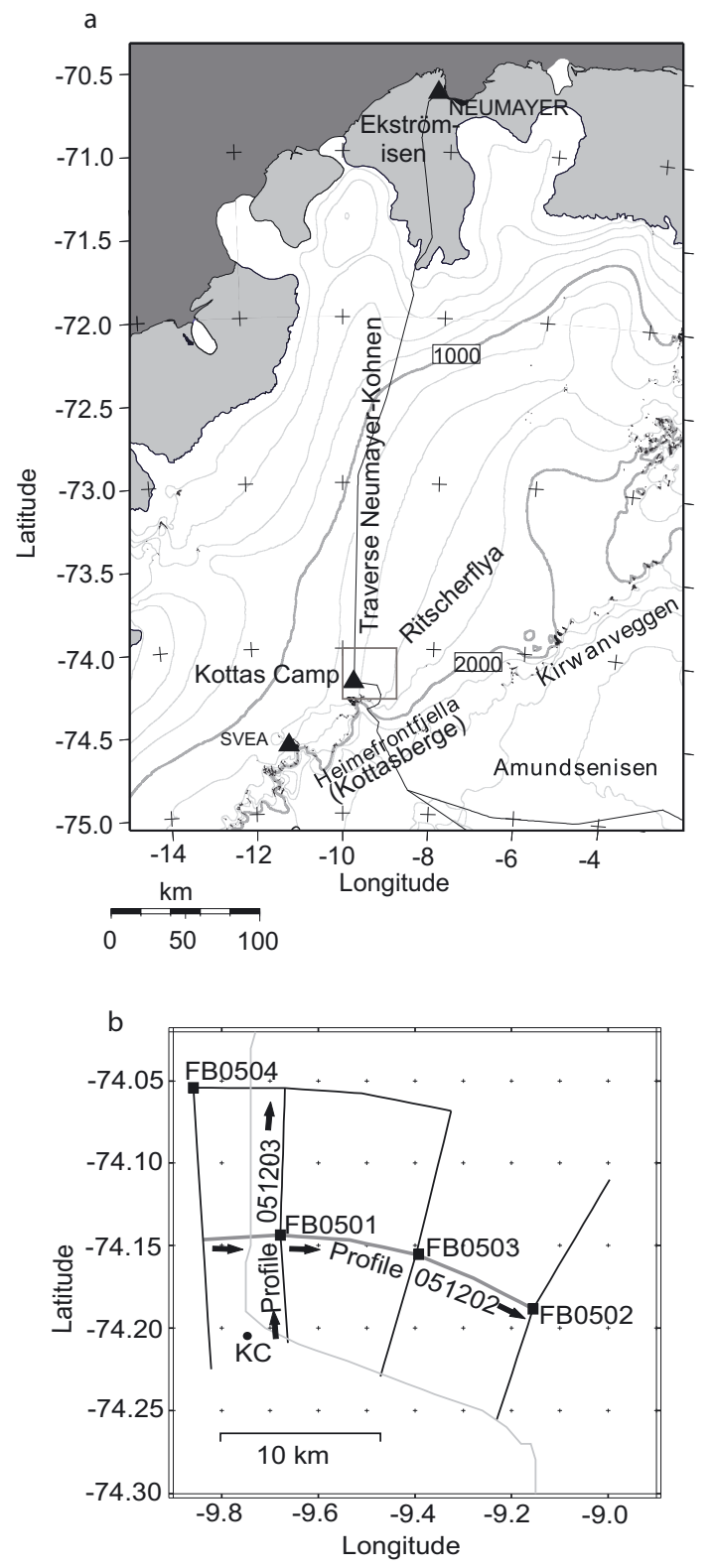

Fig. 1. (a) Thin grey curves: elevation contours at $200 \mathrm{~m}$ spacing; thick grey curves: $1000 \mathrm{~m}$ and $2000 \mathrm{~m}$ contours. The black curve indicates the traverse route from Neumayer station to Kohnen station (not shown). (Source: Antarctic Digital Database 4.0.) (b) GPR profiles and firn-core locations. Thick grey curve: profile on the ice flowline (measured against the flow direction); thin grey curve: stake line along traverse route Neumayer-Kottasberge. Arrows indicate direction of GPR profiles. Glacier flow is from right to left. KC: Kottas Camp and drilling location of FB9802.

accumulation rate for a particular period can therefore be calculated.

In this paper, we present ground-based data comprising GPR profiles and shallow firn cores from a small grid on Ritscherflya in western Dronning Maud Land (DML), Antarctica. Accumulation rates are obtained along tracked IRHs which are dated by firn-core parameters. We discuss the spatial variability of accumulation rates on the scale of a few kilometres and the temporal variability on decadal scales. Interannual variability of accumulation rates obtained from dated firn cores is also presented. We compare our results with other nearby studies from western DML as well as with similarly obtained data from a coastal site in central DML.
Table 1. Rates of volume change (in $\mathrm{km}^{3} \mathrm{a}^{-1}$ ) and uncertainties for WAIS and EAIS from GRACE

\begin{tabular}{lrr}
\hline Study & WAIS & EAIS \\
\hline Velicogna and Wahr (2006) & $-148 \pm 21$ & $0 \pm 56$ \\
Chen and others (2006) & $-77 \pm 14$ & $+80 \pm 16$ \\
Ramillien and others (2006) & $-107 \pm 23$ & $+67 \pm 28$ \\
\hline
\end{tabular}

\section{STUDY AREA}

The area of investigation is located near Kottas Camp in the grounded coastal part of DML, approximately $10 \mathrm{~km}$ north of Kottasberge, part of the Heimefrontfjella mountain range. Figure 1a depicts an overview of the area, where the dark grey rectangle corresponds to the area depicted in Figure $1 \mathrm{~b}$. This area is characterized by gentle surface undulations at 1400-1560 m a.s.l. and a glacier flow velocity of $50 \mathrm{~m} \mathrm{a}^{-1}$. The distance to the Weddell Sea coast is about $300 \mathrm{~km}$. Ice thickness in the area of investigation reaches $2000 \mathrm{~m}$ with a smooth bedrock topography (Steinhage and others, 2001).

The Heimefrontfjella mountain range marks the boundary between the inland ice plateau (Amundsenisen) and Ritscherflya, with the mountains damming the ice flow from the plateau by channelling it through small outlets. The mountain chains are directed from the southwest to the northeast. Ice-sheet altitudes range from $>2500 \mathrm{~m}$ on Amundsenisen to $1200-1500 \mathrm{~m}$ at the foot of the mountains.

\section{DATA AND METHODS GPR and GPS}

In the Antarctic summer season 2004/05, GPR measurements were carried out along an ice flowline and on cross-profiles (Fig. 1b) using a bistatic shielded $500 \mathrm{MHz}$ antenna (RAMAC, Malå Geoscience, Sweden) which was pulled by a snow vehicle at an average speed of $\sim 5 \mathrm{~km} \mathrm{~h}^{-1}$. Traces were recorded every $0.5 \mathrm{~m}$ in a time window of $400 \mathrm{~ns}$, triggered by an odometer. Simultaneously, kinematic GPS data were collected at a sampling interval of $1 \mathrm{~s}$ using a Trimble 4000SSi receiver and a choke-ring antenna. The roving station was mounted on the snow vehicle, and the reference station was located on Weigel Nunatak, $10 \mathrm{~km}$ south of Kottas Camp (Fig. 1).

Global positioning system (GPS) data provided information about the surface elevation and horizontal positions along the GPR profiles. The offset between the GPS and GPR antennae was taken into account for the positioning of the GPR traces. GPR data were filtered using a bandpass Butterworth filter with cut-off frequencies of 350 and $850 \mathrm{MHz}$, automatic gain control (AGC) and correction for the first arrival of the direct wave. From the processed GPR data, IRHs were tracked throughout the GPR profiles where possible. Conversion of travel time to depth is given below. However, the uppermost layers (up to 1.5-2 m depth) are not visible in the radargram since they are lost within the time window of the direct wave. We restrict ourselves to the upper $12 \mathrm{~m}$ since this is the maximum depth of isochronous layers which can be dated using the firn cores (see below). On the profile 051202, four IRHs are tracked within this depth range (Fig. 2) against the ice-flow direction on a flowline (Fig. 1b). 


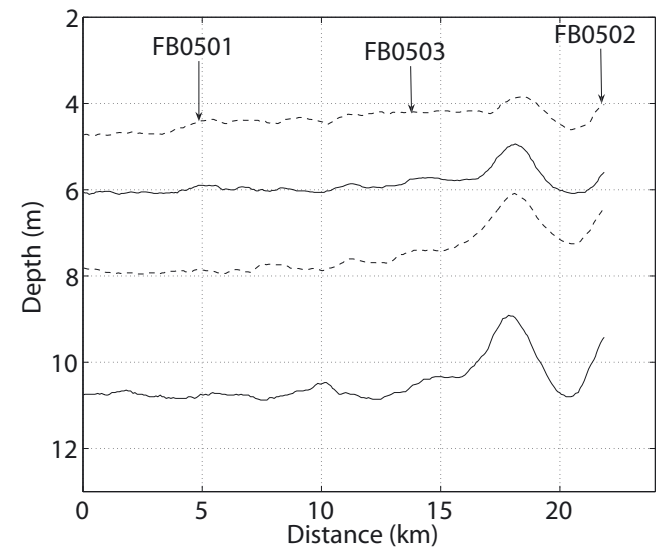

Fig. 2. Depth distribution of the tracked IRHs for profile 051202. The solid horizons are used to calculate accumulation rate.

\section{Firn cores}

At four selected points (Fig. 1b; Table 2) of the GPR profiles, shallow firn cores were drilled to depths of 12.0-12.7 m.

Firn-core analyses included density measurements using $\gamma$-attenuation profiling (GAP) over intervals of $2 \mathrm{~mm}$ and dielectric profiling (DEP) over $5 \mathrm{~mm}$ intervals (Wilhelms, 1996, 2005), yielding information about density, dielectric permittivity and the electrical conductivity of the firn. Chemical profiling was performed using a combination of continuous flow analyses (CFA) and ion chromatography (IC) (Ruth and others, 2004). Mass spectrometry was used to derive a $\delta^{18} \mathrm{O}$ profile for each core with a sample size of $25-30 \mathrm{~mm}$. Firncore parameters from firn core FB0501 are exemplified in Figure 3.

Cumulative snow mass (i.e. the mass of overlying snow/firn up to a certain depth) was obtained by integrating GAP density profiles. Radar wave speed was calculated from the profiles of dielectric permittivity, to convert two-way travel time (TWTT) of tracked IRHs to depth and cumulative mass, following Eisen and others (2002) and Anschütz and others (2007), respectively. To establish models for TWTT-depth and cumulative mass-depth the mean profiles of density and dielectric permittivity for all four firn cores were used, since there is no further information about lateral variations of those variables between the drilling sites. However, profiles of density and dielectric permittivity show only small deviations between the four firn cores. In general, fluctuations within one specific core are higher than differences between the firn cores at the same depth (not shown).

Table 2. Locations of firn cores

\begin{tabular}{lllc}
\hline Firn core & Longitude & Latitude & WGS84* \\
& & & $\mathrm{m}$ \\
\hline FB0501 & -9.6786 & -74.1438 & 1447 \\
FB0502 & -9.1556 & -74.1885 & 1569 \\
FB0503 & -9.3977 & -74.1555 & 1488 \\
FB0504 & -9.8585 & -74.0541 & 1420
\end{tabular}

World Geodetic System 1984 elevation.
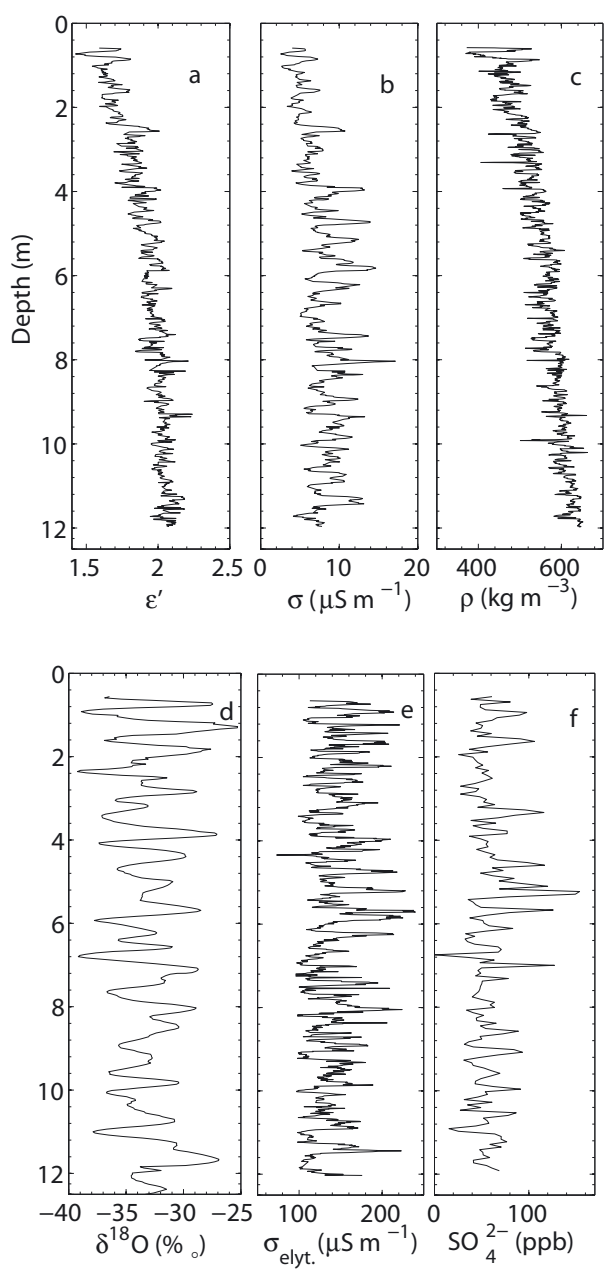

Fig. 3. Firn-core parameters from FB0501: (a) dielectric permittivity (from DEP); (b) electrical conductivity (from DEP); (c) density (from $\mathrm{GAP}$ ); (d) $\delta^{18} \mathrm{O}$ profile; (e) electrolytical conductivity (from CFA); and (f) sulphate (from IC).

\section{Determination of accumulation rates}

The $\delta^{18} \mathrm{O}$ profile and the chemical profiles of FB0501 (Fig. 3d-f) have been used to establish a depth-age scale as a dating reference for the tracked IRHs on profiles 051202 and 051203 (cross-profile; see Fig. 1b). However, unambiguous dating was not possible by the chemical profiles alone. The chemical profiles were therefore used to support the dating based on the $\delta^{18} \mathrm{O}$ profiles. Dating of the firn cores was carried out by annual-layer counting, with the $\delta^{18} \mathrm{O}$ peaks indicating summer maxima. The density profiles of the firn cores were used to calculate annual accumulation rates from the snow mass of the annual layers. Note that the firn cores do not reach up to the year 2005 (the age of the surface at the time of data collection) due to poor core quality in the upper 1-2 m. A mean accumulation rate was therefore used to estimate the age of the first datable layer, obtained from two nearby snow pits. Strain rates for this particular area are unknown, so they are not taken into account in our calculation of accumulation rates. As we are focusing on shallow depths, layer thinning can be assumed to be negligible.

Using the depth-age scale obtained from the dated firn cores, the IRHs were dated by comparing their depth values at the coring location with the age given by the depth-age 
Table 3. Accumulation values obtained from GPR (standard deviation at $1 \sigma$ level given as per cent of the mean)

\begin{tabular}{|c|c|c|c|c|c|}
\hline \multirow[t]{2}{*}{ Profile } & \multirow[t]{2}{*}{ Time period } & \multicolumn{4}{|c|}{ Accumulation } \\
\hline & & $\begin{array}{c}\text { Mean } \\
\mathrm{kg} \mathrm{m}^{-2} \mathrm{a}^{-1}\end{array}$ & $\begin{array}{l}\text { SD } \\
\%\end{array}$ & $\begin{array}{c}\text { Min. } \\
\mathrm{kg} \mathrm{m}^{-2} \mathrm{a}^{-1}\end{array}$ & $\begin{array}{c}\text { Max. } \\
\mathrm{kg} \mathrm{m}^{-2} \mathrm{a}^{-1}\end{array}$ \\
\hline 051202 & 1980-90 & 209 & 7 & 171 & 226 \\
\hline 051202 & 1990-2005 & 176 & 5 & 145 & 185 \\
\hline 051202 & 1980-2005 & 191 & 5 & 159 & 199 \\
\hline 051203 & 1980-90 & 192 & 11 & 135 & 232 \\
\hline 051203 & 1990-2005 & 170 & 12 & 139 & 234 \\
\hline 051203 & 1980-2005 & 170 & 9 & 149 & 220 \\
\hline
\end{tabular}

scale. Accumulation rates along GPR profiles were calculated by dividing their cumulative mass difference by their age difference. Following the approach of earlier studies, the isochronous property of the IRHs on profile 051202 was tested by comparing the age of the two IRHs at the positions of FB0501, FB0502 and FB0503, yielding differences of up to \pm 1 year which is within the range of the dating uncertainties. We thus regard the IRHs as isochrones.

In order to account for temporal differences td of accumulation rates of IRH intervals along the GPR profiles, we define

$$
\mathrm{td}=\frac{a\left(t_{1}\right)-a\left(t_{2}\right)}{a\left(t_{2}\right)} \times 100 \%,
$$

where a denotes accumulation along the profile and $t_{\mathrm{i}}$ the respective time period.

Calculation of errors in accumulation rates follows the discussion of Anschütz and others (2007). Deviation of the density profiles from the different firn cores is as large as 7\%, including measurement errors from GAP (up to $10 \mathrm{~kg} \mathrm{~m}^{-3}$; Wilhelms, 2005). This value represents the errors introduced by local density fluctuations with respect to the mean density profile used for the calculation of cumulative mass-depth. Errors from DEP measurements are $1 \%$ or less (Wilhelms, 1996), and conversion from TWTT to depth likewise yields errors of $1 \%$ (Eisen and others, 2002). Conversion of the tracked IRHs to cumulative mass results in errors of $\sim 1 \%$ (Anschütz and others, 2007). The dating uncertainty for the IRHs used here is \pm 1 year and the uncertainty in tracking the IRHs is up to $\pm 2 \mathrm{~ns}$, equivalent to a depth uncertainty of about $\pm 0.2 \mathrm{~m}$. The latter introduces an additional uncertainty of another \pm 1 year with respect to the depth-age scale of FB0501. Using the values given above, measurement and

Table 4. Accumulation values obtained from firn cores (standard deviation at $1 \sigma$ level given as per cent of the mean)

\begin{tabular}{|c|c|c|c|c|c|}
\hline \multirow[t]{3}{*}{ Firn core } & \multirow[t]{3}{*}{ Time period } & \multicolumn{4}{|c|}{ Accumulation } \\
\hline & & Mean & SD & Minimum & Maximum \\
\hline & & $\mathrm{kg} \mathrm{m}^{-2} \mathrm{a}^{-1}$ & $\%$ & $\mathrm{~kg} \mathrm{~m}^{-2} \mathrm{a}^{-1}$ & $\mathrm{~kg} \mathrm{~m}^{-2} \mathrm{a}^{-1}$ \\
\hline FB0501 & 1976-2003 & 221 & 28 & 108 & 328 \\
\hline FB0502 & 1976-99 & 227 & 32 & 98 & 370 \\
\hline FB0503 & 1970-2002 & 199 & 28 & 96 & 359 \\
\hline FB0504 & 1984-99 & 195 & 33 & 112 & 305 \\
\hline
\end{tabular}
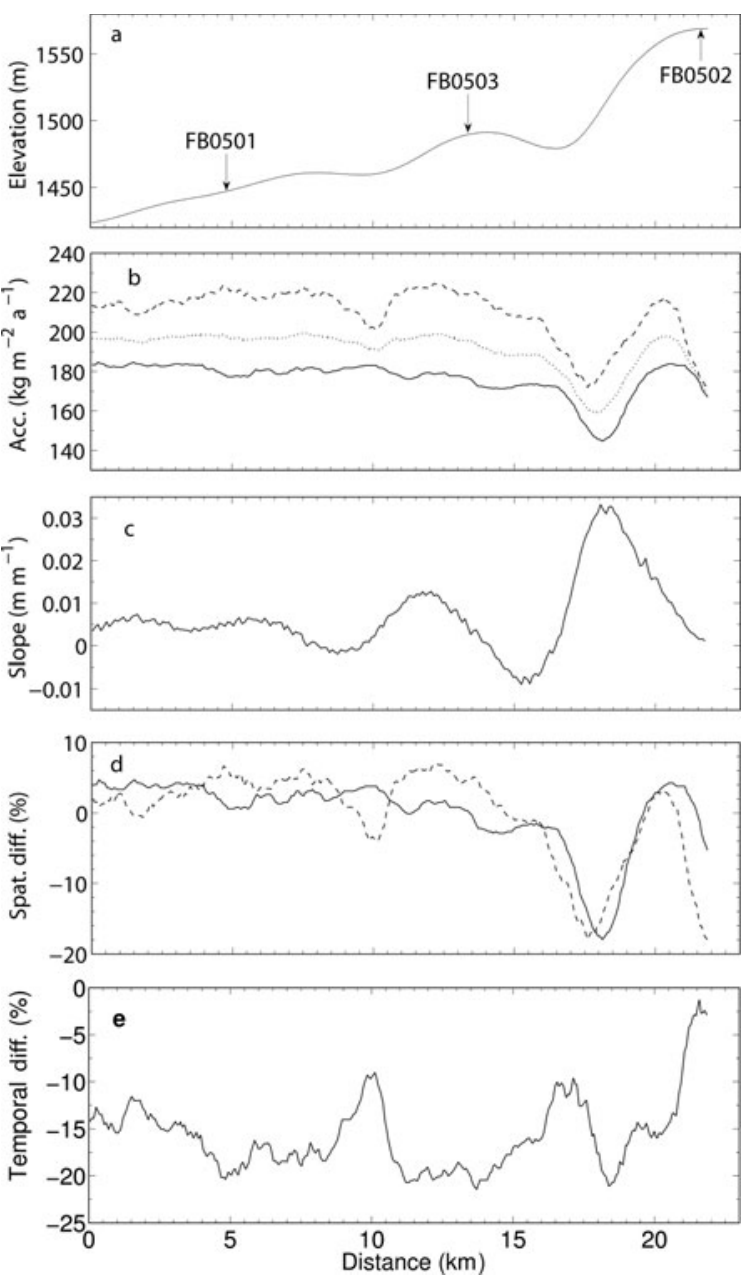

Fig. 4. (a) Surface elevation along profile 051202 near Kottas Camp, from west to east; (b) accumulation: 1980-90 (dashed curve), 19802005 (dotted curve) and 1990-2005 (solid curve); (c) surface slope; (d) spatial differences in per cent of the respective mean for the time periods 1990-2005 (solid curve) and 1980-90 (dashed curve); and (e) temporal differences between 1980-90 and 1990-2005, calculated from Equation (1). The locations of firn cores FB0501, FB0502 and FB0503 are given in (a). FB0501 marks the intersection with profile 051203 (Fig. 5).

model errors result in a mean error of $10-15 \%$ for the accumulation data presented here, similar to that reported by Anschütz and others (2007) for a different area.

\section{RESULTS}

We focus on the accumulation rates obtained from the firn cores and the two IRHs of profile 051202 (Fig. 2, solid curves). Due to ambiguities in tracing the IRHs throughout the GPR profiles and dating uncertainties, the two other IRHs are omitted. For comparison, we also present accumulation data from the cross-profile 051203 (see Fig. 1b). The two profiles intersect at the drilling location of FB0501. The estimated time of origin of the two IRHs represented by the solid curves in Figure 2 is $1980 \pm 1$ and $1990 \pm 1$ years, respectively. GPR-based accumulation rates are given in Table 3 for profiles 051202 and 051203 . The accumulation rates presented here are horizontally averaged over $5 \mathrm{~m}$.

The spatial variability of the accumulation values can be expressed by the standard deviation ( $1 \sigma$ level), which amounts to $5-7 \%$ of the respective mean value for profile 

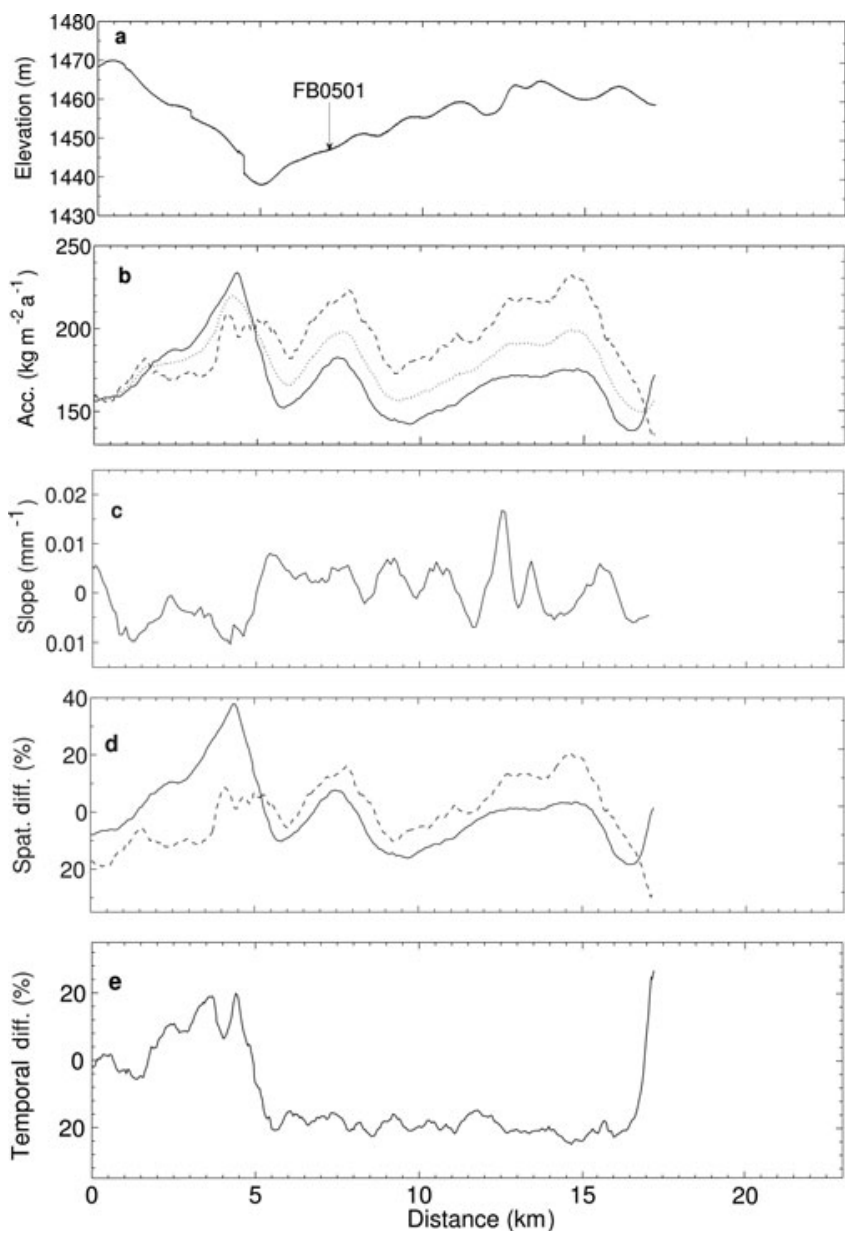

Fig. 5. (a) Surface elevation along profile 051203 near Kottas Camp, from south to north, and crossing profile 051202 perpendicularly at FB0501; (b) accumulation: 1980-90 (dashed curve), 1980-2005 (dotted curve) and 1990-2005 (solid curve); (c) surface slope; (d) spatial differences in per cent of the respective mean for the time periods 1990-2005 (solid curve) and 1980-90 (dashed curve); and (e) temporal differences between 1980-90 and 1990-2005, calculated from Equation (1). The location of firn core FB0501 is given in (a).

051202 (Table 3). Along this profile, spatial differences of the mean value for time periods 1980-90 and 1990-2005 vary from $-18 \%$ to $+8 \%$ (Fig. 4 d). The cross-profile 051203 reveals accumulation values that are in the same range compared to those on profile 051202, but with a slightly higher spatial variability, as expressed by a standard deviation of approximately $10 \%$ (Table 3 ). Here, the spatial differences for the time periods 1980-90 and 1990-2005 show values between $-30 \%$ and $+38 \%$ of the mean (Fig. $5 \mathrm{~d}$ ).

Mean accumulation values of the four firn cores as well as minima and maxima are given in Table 4. The interannual variability derived from the dated firn cores (Fig. 6a and b) is one order of magnitude higher than the spatial variability along the connecting GPR profile (Table 4), emphasizing that accumulation rates exhibit large fluctuations on annual scales. To gather information about temporal variations averaged over the projected mission duration of GRACE and ICESat, we apply a 5 year running mean to the accumulation series of FB0501, FB0502 and FB0503 (Fig. 6d). The standard deviations of the 5 year running means show values of $14 \%$ (FB0501), 12\% (FB0502) and 17\% (FB0503).
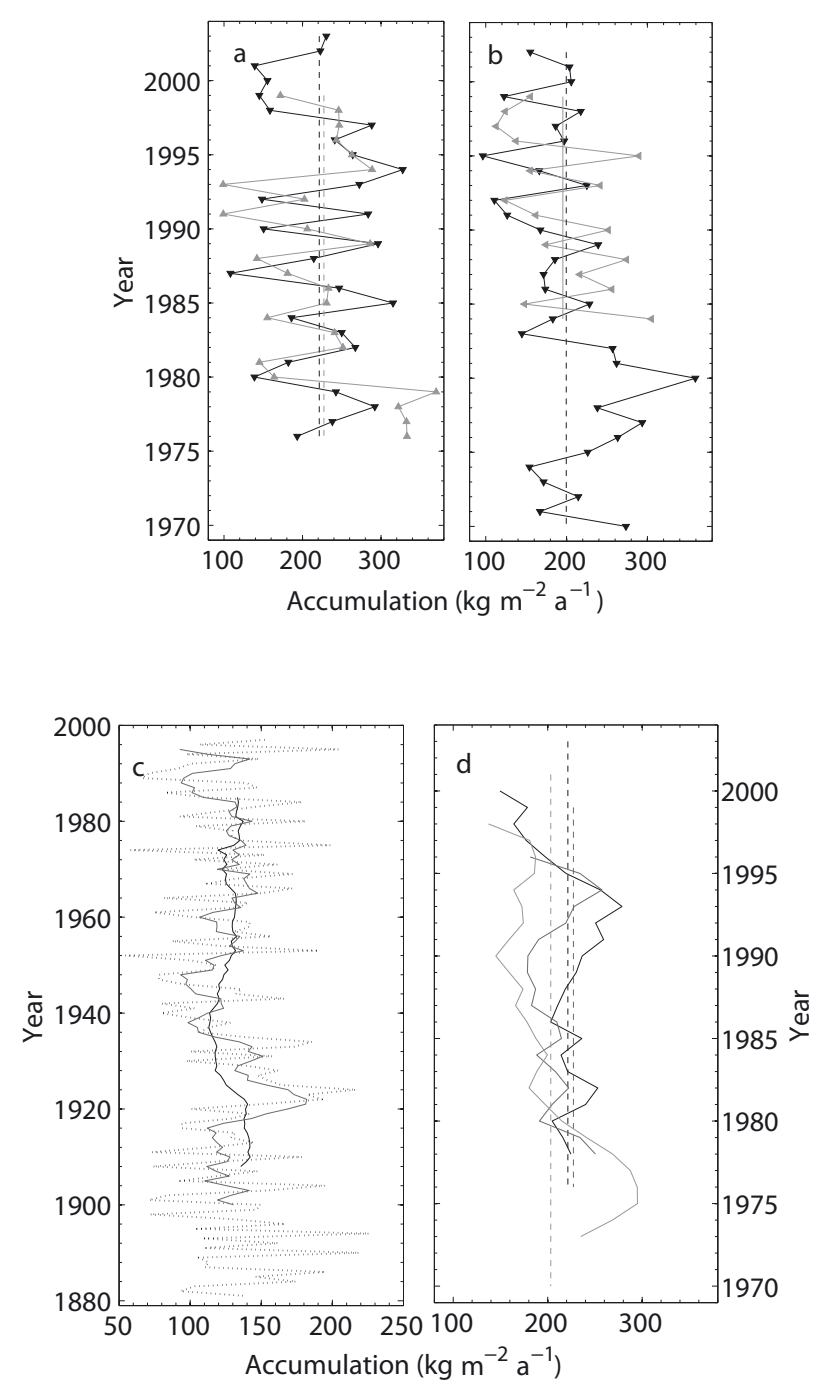

Fig. 6. (a) Year-to-year accumulation: FB0501 (solid black curve), FB0502 (solid grey curve), mean of FB0501 (dashed black curve), mean of FB0502 (dashed grey curve); (b) year-to-year accumulation: FB0503 (solid black curve), FB0504 (solid grey curve), mean of FB0503 (dashed black curve), mean of FB0504 (dashed grey curve); (c) FB9802: annual accumulation rates (dotted curve), 5 year running mean (dark grey curve), 25 year running mean (black curve) (Oerter and others, 1999); and (d) 5 year running mean of FB0501 (black solid curve), FB0502 (dark grey solid curve) and FB0503 (light grey solid curve). Mean values are shown as dashed curves with the respective shading.

\section{DISCUSSION}

The accumulation pattern on the ice flowline near Kottas Camp is quite smooth (Fig. 4b), except for the local minimum between 17 and $22 \mathrm{~km}$. This feature can be explained by the surface elevation profile (Fig. 4a; elevation above WGS84 ellipsoid) which shows a steeper increase along this section. Since the discussed IRHs are very shallow (Fig. 2) compared to the ice thickness (Steinhage and others, 2001), the ice thickness is only varying slowly. We therefore propose that the local variations in accumulation observed here arise mainly from the surface undulations and the interaction of surface topography and wind influence (e.g. King and others, 2004).

In general, the wind field and especially predominant wind direction significantly influence the accumulation pattern 
(e.g. King and others, 2004). An accumulation profile along the main wind direction should therefore exhibit accumulation maxima at local surface elevation troughs and on the windward sides of surface undulations, whereas accumulation minima are to be expected on hills and on the leeward sides. Such patterns have been discussed in several studies throughout Antarctica (e.g. Black and Budd, 1964; Pettré and others, 1986; Eisen and others, 2005; Frezzotti and others, 2007).

Van den Broeke and Van Lipzig (2004) report predominantly easterly winds in this area of Antarctica, but the horizontal resolution of their model is about $55 \mathrm{~km}$, which does not capture small-scale effects. Predominantly easterly winds agree only partly with the distribution of accumulation and surface features along profile 051202, from west to east (Fig. 4). Interestingly, accumulation pattern and surface topography show more coincidence along profile 051203, from south to north (Fig. 5). However, local wind field is unknown and the nearby Kottasberge are capable of modifying the regional wind direction. Assuming katabatic wind flow down from the nearby plateau region south of Kottasberge, the accumulation pattern of profile 051203 can be explained by wind influence. However, King and others (2004) show that correspondence between surface slope and accumulation is rather complex, especially if climatological wind direction and profile direction do not concur.

Another reason for the deviation from the general pattern on profile 051202 probably arises from consideration of glacier flow velocity. We used a mean surface flow speed of $50 \mathrm{~m} \mathrm{a}^{-1}$ to correct our GPR layers and derive accumulation rates on profile 051202 . This value is only determined by GPS observations of one reference point on the ice flowline during the expedition and might vary locally (personal communication from L. Eberlein, 2005). We therefore assume that interaction of local wind pattern and surface topography significantly influences the local accumulation pattern.

\section{Comparison with nearby studies}

Oerter and others (1999) report accumulation values at Kottas Camp of $129 \mathrm{~kg} \mathrm{~m}^{-2} \mathrm{a}^{-1}$, with a standard deviation of $29 \%$, obtained from a firn core (FB9802) drilled in December 1997 covering the time period 1881-1997. Similar to our firn cores, a 5 year running mean has also been applied to FB9802. To account for the timescales covered by our GPR data, we also apply a 25 year running mean to the accumulation series of FB9802 to enable a better comparison of temporal variations between GPR and firn-core data. The 5 year running mean and 25 year running mean of FB9802 show standard deviations of $14 \%$ and $6 \%$ of the core mean, respectively. Hence, firn core FB9802 reveals a rather smooth accumulation pattern on longer timescales and a high annual variability (Fig. 6c).

Together with our firn cores, this indicates that the temporal accumulation pattern on scales of 5-25 years is fairly stable, most probably because post-deposition noise and interannual fluctuations are averaged out. Using a mean standard deviation of $14 \%$, as evident from the firn-core data, a surface density of $350 \mathrm{~kg} \mathrm{~m}^{-3}$ and a mean accumulation rate of $180 \mathrm{~kg} \mathrm{~m}^{-2} \mathrm{a}^{-1}$ results in height fluctuations of $\sim 7 \mathrm{~cm} \mathrm{a}^{-1}$ that can be explained by temporal accumulation variations. The response of ice flow to temporal variations in accumulation is much longer than the 5 years used for averaging accumulation series. This suggests that height changes of up to $\sim 7 \mathrm{~cm} \mathrm{a}^{-1}$ may result from interannual variations of accumulation rates that are not instantaneously balanced by ice export. Accordingly, this result has implications for the correct interpretation of satellite-derived mass and elevation changes in this area.

Comparison of the standard deviation for the 25 year running mean of FB9802 with the spatial variability of our GPRderived accumulation rates shows that temporal variability on the scale of decades and spatial variability on the scale of $20 \mathrm{~km}$ are very similar (6\% and 5\%, respectively). In contrast, studies from the polar plateau report that spatial variability on the kilometre scale is one order of magnitude higher than temporal variability on multi-decadal scales (Frezzotti and others, 2007). We suggest that these different characteristics are due to the different areas and timescales covered by our study, as the Heimefrontfjella forms a dominant topographic feature influencing wind regimes over a large area.

Considering the area-wide mean values (Table 3), our study reveals somewhat higher accumulation rates than those reported by Oerter and others (1999). The same holds for comparison of FB9802 with our firn-core data (Table 4). In order to take into account the different time periods covered by FB9802 and our firn cores, we calculate the mean accumulation of FB9802 over 1975-97 (i.e. the time period that overlaps with our firn cores) as $126 \mathrm{~kg} \mathrm{~m}^{-2} \mathrm{a}^{-1}$. Hence, the time periods covered do not seem to be responsible for the different accumulation rates between FB9802 and our study. However, the spatial representativeness of firn cores is generally rather small (e.g. Richardson-Näslund, 2004; Rotschky and others, 2004; Spikes and others, 2004), and FB9802 is separated by $7-18 \mathrm{~km}$ from our firn-core locations and by about $3 \mathrm{~km}$ from the start of profile 051203. Comparing only accumulation rates from locations within our investigation that are nearest to FB9802, i.e. the start of profile 051203 (Fig. 1b), we derive annual accumulation rates of around $150 \mathrm{~kg} \mathrm{~m}^{-2} \mathrm{a}^{-1}$ (Fig. 5b). These values are more in accordance with the value of $129 \mathrm{~kg} \mathrm{~m}^{-2} \mathrm{a}^{-1}$ reported by Oerter and others (1999).

Rotschky and others (2006) present accumulation data obtained from stake readings along the transect from Neumayer station $\left(70^{\circ} 39^{\prime} \mathrm{S}, 08^{\circ} 15^{\prime} \mathrm{W}\right)$ to Kottas Camp and farther on to the Kottasberge mountain range (Fig. 1a). Data obtained from stakes within $20-30 \mathrm{~km}$ of our GPR profiles range from 150 to $250 \mathrm{~kg} \mathrm{~m}^{-2} \mathrm{a}^{-1}$ (Fig. 7a), with a high spatial variability. The transect up to Kottas Camp and the spatial variability of the accumulation data, complemented by GPR profiling, is further discussed by Richardson-Näslund (2004) with similar results. The stake-line data confirm the observation that in the immediate vicinity of Kottas Camp, accumulation values are slightly lower. Moreover, Rotschky and others (2007) obtained an accumulation map of western DML by interpolation of all available firn-core data, reporting values of about $180 \mathrm{~kg} \mathrm{~m}^{-2} \mathrm{a}^{-1}$ for our investigation area. Our study therefore provides values within the range of current observations, but contributes a variability of accumulation rates on smaller spatial and temporal scales than has been previously published.

\section{Temporal variation of spatial characteristics}

We consider the temporal difference $t d$, as defined by Equation (1), of GPR-based accumulation rates on profile 051202 between the time intervals $t_{1}=1990-2005$ and $t_{2}=1980-$ 90. The result is a mean value of $-16 \%$, i.e. accumulation rates in the time period $t_{1}$ are on average $16 \%$ lower than during $t_{2}$. This value is not constant along the profile 051202 , 


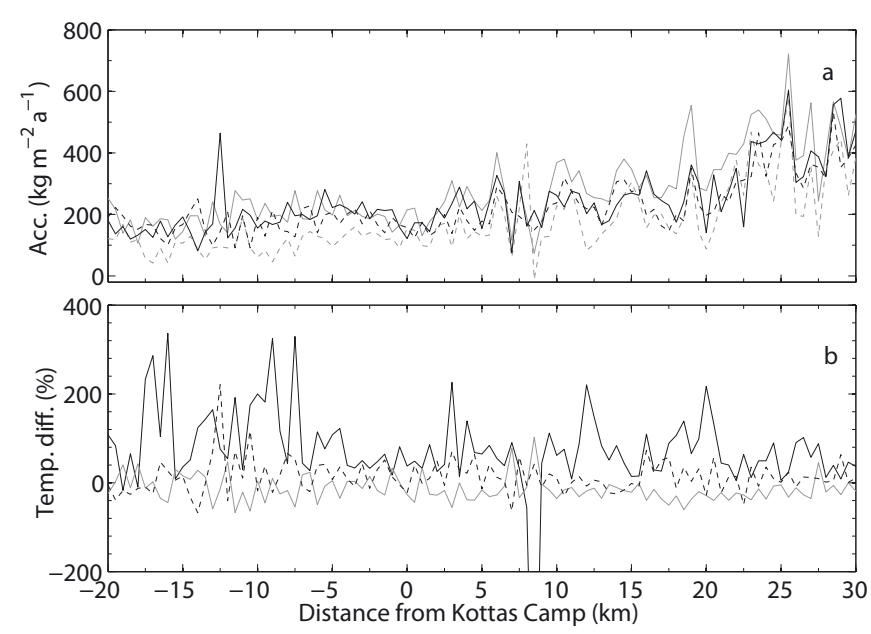

Fig. 7. (a) Accumulation values from stakeline readings in the vicinity of Kottas Camp: 1998 (black solid curve), 1999 (black dashed curve), 2000 (grey solid curve), 2001 (grey dashed curve). (b) Temporal differences calculated as in Equation (1): 1998-99 (black solid curve), 1999-2000 (grey solid curve), 2000-01 (black dashed curve). Negative values on the abscissa correspond to stakes located north of Kottas Camp; positive values are stakes to the south.

however. In fact, considering td pointwise along 051202 we see that temporal variations range from $-1.3 \%$ to $-23 \%$ (Fig. 4d). Comparing spatial and temporal differences along this profile, the variations seem to be linked, i.e. the largest temporal differences tend to occur at the places with largest relative spatial differences. Analysis of $t d$ on the cross-flow profile 051203 results in similar findings: the temporal differences likewise vary locally. Spatio-temporal characteristics of the stake-line data within $20-30 \mathrm{~km}$ around Kottas Camp (Fig. 7) confirm this observation, showing again a quite similar pattern of spatial and temporal accumulation, for instance between -15 and $-10 \mathrm{~km}$ and $\sim 20 \mathrm{~km}$.

Caution should be exercised with this comparison, however, as the stake-line data yield only annual variability whereas our GPR data consider decadal variability. In total, it seems that the spatial characteristics of accumulation are not constant in time in the considered region and timescales. Thus, it is important to derive the temporal differences pointwise along profiles and not only from the mean values. Smallscale features seem to affect both the temporal pattern and the spatial distribution.

Accumulation rates have been obtained likewise by combined analysis of GPR and firn-core studies on Potsdam Glacier, a near-coastal site in central Dronning Maud Land, in 2003/04. Similar to the area near Kottas Camp, the investigation area on Potsdam Glacier is characterized by the down-flow of ice from the polar plateau through mountain ranges. The spatial variability is discussed in detail by Anschütz and others (2007), reporting standard deviations of about $50 \%$ which is one order of magnitude higher than the standard deviations along the GPR profiles near Kottas Camp. On Potsdam Glacier, spatial differences from the respective mean value vary from -87 to $+128 \%$ for the time period $1970-80$ and from -79 to $+130 \%$ for $1980-2004$ (Fig. 8b). The temporal variation of accumulation rate of a few per cent as reported by Anschütz and others (2007) is obtained from the area-wide mean values of the time periods 1970-80 and 1980-2004, yet analysis of temporal variations

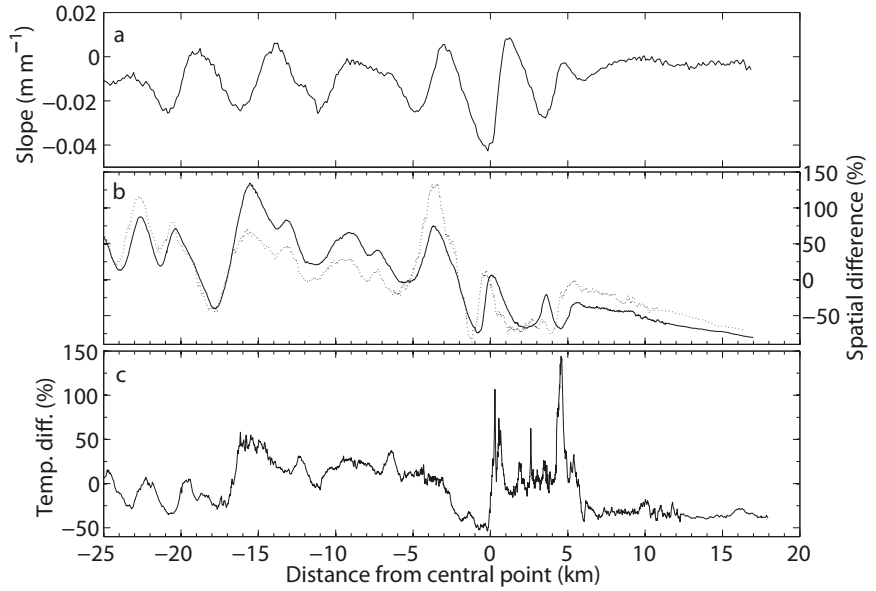

Fig. 8. (a) Main Potsdam Glacier flowline slope. (b) Potsdam Glacier accumulation spatial variation, expressed as differences from the mean, in per cent of the mean: 1980-2004 (solid curve) and 197080 (dashed curve). (c) Temporal variations between the time periods 1970-80 and 1980-2004 as calculated from Equation (1).

along the profile on the main glacier flowline yields a varying pattern (Fig. 8c) as at Kottas Camp. The mean temporal difference of accumulation rates on Potsdam Glacier for the observed time periods $t_{1}$ and $t_{2}$ amounts to $-3 \%$, with values varying from $-53 \%$ up to as much as $+145 \%$, as calculated from Equation (1) with $t_{1}=1980-2004$ and $t_{2}=1970-80$. Again, the largest temporal variations occur near maxima of spatial variability, indicating that temporal and spatial variations are not independent on these scales. The point-to-point variations of the temporal accumulation pattern near Kottas Camp (Figs 4e and 5e) exhibit less pronounced differences compared to those on Potsdam Glacier (Fig. 8c).

Anschütz and others (2006) discuss the influence of the surface topography on the spatial accumulation pattern on Potsdam Glacier and find dune-like features of relatively short distance between troughs, comparable to the megadunes observed on the polar plateau (Frezzotti and others, 2002). Upstream migration of these dunes at an average rate of $45 \mathrm{~m} \mathrm{a}^{-1}$ (Anschütz and others, 2006) as well as locally varying glacier flow speed might also influence the variations in temporal accumulation observed on Potsdam Glacier.

Comparing the spatial and the temporal variations on Potsdam Glacier (Fig. 8b and c) and near Kottas Camp (Figs 4d and $\mathrm{e}$ and $5 \mathrm{~d}$ and e) with the respective surface slopes (Figs $8 \mathrm{a}, 4 \mathrm{c}$ and $5 \mathrm{c}$ ), we suggest that in areas of strong interaction between surface elevation, slope and accumulation, temporally varying mean accumulation rates lead to changing spatial accumulation patterns.

In order to analyze a possible correlation between spatial and temporal variations, we calculate the correlation coefficients $R$ for spatial differences, in per cent, of the respective mean and temporal differences td along the GPR profiles near Kottas Camp and on Potsdam Glacier. We obtain values of $0.24\left(t_{1}=1990-2005\right)$ and $0.69\left(t_{2}=1980-90\right)$ for profile 051202 and correlation coefficients of $0.66\left(t_{1}=1990\right.$ $2005)$ and $0.55\left(t_{2}=1980-90\right)$ for profile 051203 near Kottas Camp. The profile on the glacier flowline of Potsdam Glacier reveals $R=0.48$ for $t_{1}=1980-2004$ and $R=0.28$ for $t_{2}=1970-1980$.

This indicates that spatial and temporal variations are at least weakly correlated in our investigation areas. However, 
inaccuracies of glacier flow velocity as well as dating uncertainties prevent a more detailed investigation. Influence of two-dimensional topography on accumulation rates might also be responsible for the observed spatio-temporal accumulation pattern. The topography in some of our investigation area can only be determined in high resolution along the GPR/GPS profiles, however. Due to the spacing between the profiles and the lack of a sufficient digital elevation model, we are unable to discuss possible small-scale topographical effects on our accumulation pattern.

Several other studies discussing temporal and spatial accumulation characteristics find different results. Vaughan and others (2004) reported accumulation data from Lyddan Ice Rise where spatial and temporal variability can be separated. They found that the regional mean accumulation is modified locally by persistent spatial variation and a non-persistent residual variability which is most likely due to minor changes in wind regime. As we do not have wind data for our investigation areas, we cannot determine whether our profiles are aligned with the main wind direction.

The results of Eisen and others (2005) on the East Antarctic plateau and Spikes and others (2004) in West Antarctica also indicate that spatial and temporal variability are separable. At this point we are unable to determine whether our findings are representative for larger areas of the grounded coastal parts of the Antarctic ice sheet. We therefore suggest that in our investigation areas the influence of surface topography, wind field and glacier flow are responsible for the relation between spatial and temporal accumulation pattern.

Near-surface winds tend to be complicated in nunatakdominated areas (Jonsson, 1995), as would be seen on Potsdam Glacier. Since spatial variability is usually implicated when considering accumulation rates obtained from GPR (e.g. Richardson and others, 1997; Richardson-Näslund, 2004; Rotschky and others, 2004), further research is necessary to reveal possible correlations between spatial and temporal variability. As temporal variability obtained from ice-core records can be influenced by spatial variability of accumulation rates upstream of the drilling site and glacier flow (e.g. Spikes and others, 2004; Eisen and others, 2005; Frezzotti and others, 2007), detailed analysis of spatiotemporal characteristics is therefore important for the correct interpretation of climate signals obtained from ice cores.

Satellite observations such as those from GRACE allow the determination of ice-mass changes over several years with a spatial resolution of a few hundred kilometres. The spatial resolution of our ground-based observations on icemass changes is probably too low with too small a temporal overlap to validate the GRACE data. Our observations can contribute, however, to the assessment of statistical characteristics of the snow accumulation fluctuations which, in turn, is needed for the interpretation of satellite data. Icemass trends observed by satellite over a few years may be due either to interannual fluctuations in net ice surface mass balance or to long-term ice dynamics. In order to distinguish between these two effects, the temporal and spatial covariance of surface mass-balance fluctuation has to be known at least approximately.

Our GPR data analysis reveals the spatial behaviour of temporal changes in the investigation area. From Figures 4 and 5 it is evident that temporal variations can be spatially correlated over approximately $10 \mathrm{~km}$. To determine the correlation length, and to draw conclusions about a comparison with GRACE data, it would be desirable to assess the correlation characteristics over larger distances. Clearly, for variations averaged over several hundred kilometres, the small-scale variations (deposition noise) are probably averaged out, therefore the standard deviation of temporal fluctuations will be smaller than the values of $28-33 \%$ obtained from the firn-core time series (Table 4). Such large fluctuations will therefore not be observed by GRACE.

Our observations and analyses help to qualify the spatiotemporal behaviour of the ice surface mass balance in larger areas and, together with studies from adjacent regions (e.g. Oerter and others, 1999; Richardson-Näslund, 2004; Rotschky and others, 2007), will support the interpretation of GRACE (and other satellite) observations.

\section{CONCLUSIONS}

Small-scale spatial variations of the recent accumulation rate as well as decadal and interannual temporal variations on Ritscherflya obtained from combined analysis of GPR and firn-core data have been discussed. Our GPR data indicate that spatial variability in this investigation area is rather low compared with other coastal sites, yet the year-to-year accumulation values obtained from firn cores reveal a large variability. Mean accumulation rates near Kottas Camp for the time period $1980-2005$ amount to $190 \mathrm{~kg} \mathrm{~m}^{-2} \mathrm{a}^{-1}$ on the flowline profile, with a standard deviation of 5-9\%. The cross-profile yields a mean accumulation rate of $170 \mathrm{~kg} \mathrm{~m}^{-2} \mathrm{a}^{-1}$ and a standard deviation of $9 \%$ for the same time period. Our results confirm the values from previous studies and provide additional detailed information about small-scale spatial and temporal variability.

We find that temporal fluctuations of accumulation coincide widely with spatial variations in our investigation area. Comparison with surface elevation and slope suggests that temporally varying accumulation rates lead to changes in the spatial pattern. It remains to be investigated how representative this result is for larger areas of Antarctica.

Furthermore, our results indicate that height changes of up to $7 \mathrm{~cm} \mathrm{a}^{-1}$ may not be due to actual elevation changes but to accumulation variability in this area. This has implications for validation of satellite-based estimates of mass and elevation changes. Our study therefore provides valuable insight into local characteristics of temporal and spatial accumulation patterns, supporting the interpretation of satellite data and of ice-core records.

\section{ACKNOWLEDGEMENTS}

This work was supported by the Deutsche Forschungsgemeinschaft (DFG) through the VISA project, funded under grants Di 473/17 and Jo 191/8. O.E. was supported by the DFG 'Emmy Noether' programme. M. Scheinert (TU Dresden) provided the processed GPS data. B. Bayer is thanked for help with the figures. The support of the field team and in the ice laboratory is gratefully acknowledged. Comments from D. Vaughan and O. Brandt led to great improvements in the manuscript.

\section{REFERENCES}

Alley, R.B., P.U. Clark, P. Huybrechts and I. Joughin. 2005. Ice-sheet and sea-level changes. Science, 310(5747), 456-460.

Anschütz, H., O. Eisen, W. Rack and M. Scheinert. 2006. Periodic surface features in coastal East Antarctica. Geophys. Res. Lett., 33(22), L22501. (10.1029/2006GL027871.) 
Anschütz, H., O. Eisen, H. Oerter, D. Steinhage and M. Scheinert. 2007. Investigating small-scale variations of the recent accumulation rate in coastal Dronning Maud Land, East Antarctica. Ann. Glaciol., 46, 14-21.

Black, H.P. and W. Budd. 1964. Accumulation in the region of Wilkes, Wilkes Land, Antarctica. J. Glaciol., 5(37), 3-15.

Chen, J.L., C.R. Wilson, D.D. Blankenship and B.D. Tapley. 2006. Antarctic mass rates from GRACE. Geophys. Res. Lett., 33(11), L11502. (10.1029/2006GL026369.)

Church, J.A. and N.J. White. 2006. A 20th century acceleration in global sea-level rise. Geophys. Res. Lett., 33(1), L01602. (10.1029/2005GL024826.)

Eisen, O., U. Nixdorf, F. Wilhelms and H. Miller. 2002. Electromagnetic wave speed in polar ice: validation of the common-midpoint technique with high-resolution dielectric profiling and $\gamma$-density measurements. Ann. Glaciol., 34, 150-156.

Eisen, O., U. Nixdorf, F. Wilhelms and H. Miller. 2004. Age estimates of isochronous reflection horizons by combining ice core, survey, and synthetic radar data. J. Geophys. Res., 109(B4), B04106. (10.1029/2003JB002858.)

Eisen, O., W. Rack, U. Nixdorf and F. Wilhelms. 2005. Characteristics of accumulation rate around the EPICA deep-drilling site in Dronning Maud Land, Antarctica. Ann. Glaciol., 41, 41-56.

Frezzotti, M., S. Gandolfi and S. Urbini. 2002. Snow megadunes in Antarctica: sedimentary structure and genesis. J. Geophys. Res., 107(D18), 4344. (10.1029/2001JD000673.)

Frezzotti, M. and 13 others. 2007. Spatial and temporal variability of snow accumulation in East Antarctica from traverse data. J. Glaciol., 51(177), 113-124.

Fujita, S. and 6 others. 1999. Nature of radio-echo layering in the Antarctic ice sheet detected by a two-frequency experiment. J. Geophys. Res., 104(B6), 13,013-13,024.

Gregory, J. and P. Huybrechts. 2006. Ice-sheet contributions to future sea-level change. Philos. Trans. R. Soc. London, Ser. A, 364(1844), 1709-1731.

Isaksson, E. and W. Karlén. 1994. Spatial and temporal patterns in snow accumulation, western Dronning Maud Land, Antarctica. J. Glaciol., 40(135), 399-409.

Jonsson, S. 1995. Synoptic forcing of wind and temperature in a large cirque $300 \mathrm{~km}$ from the coast of East Antarctica. Antarct. Sci., 7(4), 409-420.

King, J.C., P.S. Anderson, D.G. Vaughan, G.W. Mann, S.D. Mobbs and S.B. Vosper. 2004. Wind-borne redistribution of snow across an Antarctic ice rise. J. Geophys. Res., 109(D11), D11104. (10.1029/2003JD004361.)

Kreutz, K.J., P.A. Mayewski, L.D. Meeker, M.S. Twickler and S.I. Whitlow. 2000. The effect of spatial and temporal accumulation rate variability in West Antarctica on soluble ion deposition. Geophys. Res. Lett., 27(16), 2517-2520.

Melvold, K., J.O. Hagen, J.F. Pinglot and N. Gundestrup. 1998. Large spatial variation in accumulation rate in Jutulstraumen ice stream, Dronning Maud Land, Antarctica. Ann. Glaciol., 27, 231-238.

Oerter, H., W. Graf, F. Wilhelms, A. Minikin and H. Miller. 1999. Accumulation studies on Amundsenisen, Dronning Maud Land, by means of tritium, dielectric profiling and stable-isotope measurements: first results from the 1995-96 and 1996-97 field seasons. Ann. Glaciol., 29, 1-9.

Pettré, P., J.F. Pinglot, M. Pourchet and L. Reynaud. 1986. Accumulation in Terre Adélie, Antarctica: effect of meteorological parameters. J. Glaciol., 32(112), 486-500.

Ramillien, G. and 6 others. 2006. Interannual variations of the mass balance of the Antarctica and Greenland ice sheets from GRACE. Global Planet. Change, 53(3), 198-208.
Richardson, C. and P. Holmlund. 1999. Spatial variability at shallow snow-layer depths in central Dronning Maud Land, East Antarctica. Ann. Glaciol., 29, 10-16.

Richardson, C., E. Aarholt, S.E. Hamran, P. Holmlund and E. Isaksson. 1997. Spatial distribution of snow in western Dronning Maud Land, East Antarctica, mapped by a ground-based snow radar. J. Geophys. Res., 102(B9), 20,343-20,353.

Richardson-Näslund, C. 2004. Spatial characteristics of snow accumulation in Dronning Maud Land, Antarctica. Global Planet. Change, 42(1-4), 31-43.

Rignot, E. and R.H. Thomas. 2002. Mass balance of polar ice sheets. Science, 297(5586), 1502-1506.

Rotschky, G., O. Eisen, F. Wilhelms, U. Nixdorf and H. Oerter. 2004. Spatial distribution of surface mass balance on Amundsenisen plateau, Antarctica, derived from ice-penetrating radar studies. Ann. Glaciol., 39, 265-270.

Rotschky, G., W. Rack, W. Dierking and H. Oerter. 2006. Retrieving snowpack properties and accumulation estimates from a combination of SAR and scatterometer measurements. IEEE Trans. Geosci. Remote Sens., 44(4), 943-956.

Rotschky, G. and 6 others. 2007. A new surface accumulation map for western Dronning Maud Land, Antarctica, from interpolation of point measurements. J. Glaciol., 53(182), 385-398.

Ruth, U. and 6 others. 2004. Comprehensive 1000 year climatic history from an intermediate-depth ice core from the south dome of Berkner Island, Antarctica: methods, dating and first results. Ann. Glaciol., 39, 146-154.

Sinisalo, A., A. Grinsted, J.C. Moore, E. Kärkäs and R. Pettersson. 2003. Snow-accumulation studies in Antarctica with groundpenetrating radar using 50, 100 and $800 \mathrm{MHz}$ antenna frequencies. Ann. Glaciol., 37, 194-198.

Spikes, V.B., G.S. Hamilton, S.A. Arcone, S. Kaspari and P. Mayewski. 2004. Variability in accumulation rates from GPR profiling on the West Antarctic plateau. Ann. Glaciol., 39, 238-244.

Steinhage, D., U. Nixdorf, U. Meyer and H. Miller. 2001. Subglacial topography, internal structure of central, western Dronning Maud Land Land, Antarctica, determined from airborne radio echo sounding. J. Appl. Geophys., 47(3-4), 183-189.

Tapley, B.D., S. Bettardpur, M. Watkins and C. Reigber. 2004. The gravity recovery and climate experiment: mission overview and early results. Geophys. Res. Lett., 31(6), L09607. (10.1029/2004GL019920.)

Thomas, R. and 17 others. 2004. Accelerated sea level rise from West Antarctica. Science, 306(5694), 255-258.

Van den Broeke, M.R. and N.P.M. van Lipzig. 2004. Changes in Antarctic temperature, wind and precipitation in response to the Antarctic Oscillation. Ann. Glaciol., 39, 119-126.

Van der Veen, C.J. 2002. Polar ice sheets and global sea level: how well can we predict the future? Global Planet. Change, 32(2-3), 165-194.

Vaughan, D.G. 2005. How does the Antarctic ice sheet affect sea level rise? Science, 308(5730), 1877-1878.

Vaughan, D.G., P.S. Anderson, J.C. King, G.W. Mann, S.D. Mobbs and R.S. Ladkin. 2004. Imaging of firn isochrones across an Antarctic ice rise and implications for patterns of snow accumulation rate. J. Glaciol., 50(170), 413-418.

Velicogna, I. and J. Wahr. 2006. Measurements of time-variable gravity show mass loss in Antarctica. Science, 311(5768), 1754-1756.

Wilhelms, F. 1996. Leitfähigkeits- und Dichtemessung an Eisbohrkernen. Ber. Polarforsch. 191.

Wilhelms, F. 2005. Explaining the dielectric properties of firn as a density-and-conductivity mixed permittivity (DECOMP). Geophys. Res. Lett., 32(16), L16501. (10.1029/2005GL022808.)

Zwally, H.J. and 15 others. 2002. ICESat's laser measurements of polar ice, atmosphere, ocean and land. J. Geodyn., 34(3-4), $405-445$. 